\title{
A Nonaqueous Potentiometric Titration Study of the Dissociation of $t$-Butyl Methacrylate-Methacrylic Acid Copolymers
}

\author{
Kiyoharu Nakatani, ${ }^{* \dagger}$ Jun Yamashita,* Tomomi Sekine, $*$ Minoru Toriumi, ${ }^{* *}$ and \\ Toshiro ITANI** \\ *Department of Chemistry, University of Tsukuba, 1-1-1 Tennoudai, Tsukuba 305-8571, Japan \\ **Semiconductor Leading Edge Technologies, Inc. (Selete), 16-1 Onogawa, Tsukuba 305-8569, Japan
}

\begin{abstract}
The dissociation of $t$-butyl methacrylate-methacrylic acid copolymers in dimethyl sulfoxide was analyzed by a nonaqueous potentiometric titration technique. The negative logarithm of the dissociation constant of the monomer unit of a methacrylic acid (MAA) monotonously increased with the increasing degree of dissociation corresponding to the titrant/MAA amount ratio, and was highly influenced by the copolymerization ratio. The results are discussed in terms of the suppression of the dissociation of MAA by a neighboring charged methacrylate anion unit.
\end{abstract}

(Received December 25, 2002; Accepted February 12, 2003)

\section{Introduction}

Studying the dissociation of a polymer is significant for understanding the dissolution behavior of resist materials, proteins, membranes, synthetic colloids, and so forth. The dissociation behavior of various water-soluble polymers has been both experimentally and theoretically reported. ${ }^{1-8}$ For a resist resolution in photolithography, acid dissociation of the resist polymers is one of the important factors. Although potentiometric titration is useful as a quantitative analysis of acid dissociation, direct measurements of the acidity of resist polymers cannot be performed by aqueous potentiometric titration since the polymers do not dissolve in water. If nonaqueous potentiometric titration can be applied to resist polymers, the relationship between the dissolution in a developing alkaline solution and the acidity of the polymers can be analyzed in detail. Nonetheless, nonaqueous potentiometric titration has rarely been applied to resist polymers so far, except for a few preliminary reports..$^{910}$ In this study, nonaqueous potentiometric titration was demonstrated for $t$-butyl methacrylate-methacrylic acid copolymers (Poly$\left(\mathrm{BuMA}_{1-x} \mathrm{MAA}_{x}\right), x$; copolymerization ratio), which are typical polymers and are also used as a model of resist polymers. The copolymerization ratio dependence of the acid dissociation of Poly $\left(\mathrm{BuMA}_{1-x} \mathrm{MAA}_{x}\right)$ is discussed in detail.

\section{Experimental}

As a sample solution, dimethyl sulfoxide (DMSO) containing $\operatorname{Poly}\left(\mathrm{BuMA}_{1-x} \mathrm{MAA}_{x}\right)(x=0.33,0.40,0.46,0.60$, and 0.80$)$ with a molecular weight of $5000-6000$ was used. A methanol solution of tetrabutylammonium hydroxide (Wako Pure

† To whom correspondence should be addressed.

E-mail: nakatani@chem.tsukuba.ac.jp

M. T. present address: Daikin Industries, Ltd., Settsu 566-8585, Japan.
Chemical Industries, for non-aqueous titration) $(0.2 \mathrm{M}, 1 \mathrm{M}=1$ $\left.\mathrm{mol} / \mathrm{dm}^{3}\right)$ was injected into a stirred sample solution $\left(10 \mathrm{~cm}^{3}\right)$ using a syringe pump (kdScientific, Model 100) at a flow rate of $2 \mathrm{~cm}^{3} / \mathrm{h}$; the potential difference between a glass electrode (Horiba, 1076A-10C) and an $\mathrm{Ag} / \mathrm{Ag}^{+}$electrode (BAS, RE-5) was measured by an electrometer (Keithley, 6517 Electrometer) with time. Prior to the titration of $\operatorname{Poly}\left(\mathrm{BuMA}_{1-x} \mathrm{MAA}_{x}\right)$, salicylic acid $(12.5 \mathrm{mM})$ in DMSO was titrated with a tetrabutylammonium hydroxide solution using this experimental setup. The $\mathrm{pH}$ value calculated from the potential difference was calibrated using a dissociation constant of salicylic acid in $\operatorname{DMSO}\left(K_{\mathrm{a}}, 10^{-6.7}\right) .{ }^{11}$ All measurements were performed at room temperature $(293-295 \mathrm{~K})$.

\section{Results and Discussion}

As an organic solvent of nonaqueous potentiometric titration, methyl isobutyl ketone, DMSO, acetonitrile, and so forth are frequently used. However, the solubility of Poly$\left(\right.$ BuMA $\left._{1-x} \mathrm{MAA}_{x}\right)$ for methyl isobutyl ketone or acetonitrile was very low. For an $x$ range of $0.33-0.80$, Poly $\left(\mathrm{BuMA}_{1-x} \mathrm{MAA}_{x}\right)$ was only dissolved in DMSO; therefore, the solvent was used in the present study. Potentiometric titration curves at a concentration of $12.5 \mathrm{mM}$, as the total concentration of the monomer unit $\left(C_{\mathrm{M}}\right)$ of methacrylic acid (MAA) and $t$-butyl methacrylate (BuMA), are shown in Fig. 1. The equivalent values for $x=0.46$ and 0.80 are estimated to be 0.27 and 0.47 $\mathrm{cm}^{3}$ as the titrant volumes, respectively. Indeed, the $\mathrm{pH}$ was jumped close to the titrant volumes (Fig. 1). For a polyacid with a high molecular weight, the time required to form a stable conformation has been reported to be long. ${ }^{12}$ In the present polymers, however, the time to a stable conformation is expected to be short due to the relatively small polymers (molecular weight; 5000 - 6000). Actually, the titration curves at a titrant injection rate of $2 \mathrm{~cm}^{3} / \mathrm{h}$ were in good agreement with those of $0.8 \mathrm{~cm}^{3} / \mathrm{h}$. The $\mathrm{pH}$ was saturated at $16-17$ due to autoprotolysis in the DMSO/methanol system although the autoprotolysis constant of DMSO has been reported to be 


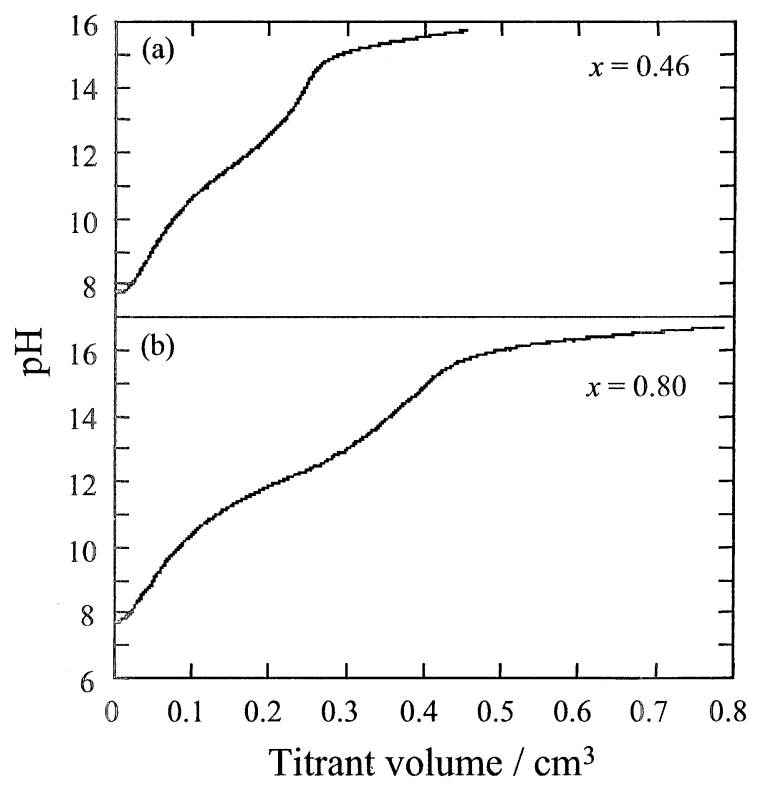

Fig. 1 Potentiometric titration curves of Poly $\left(\mathrm{BuMA}_{1-x} \mathrm{MAA}_{x}\right)$ in DMSO at $C_{\mathrm{M}}=12.5 \mathrm{mM}$ for $x=0.46$ (a) and 0.80 (b).

$10^{-30} .^{11}$ When an isopropanol solution of tetrabutylammonium hydroxide was used, the $\mathrm{pH}$ was saturated around $22 .{ }^{11}$ Because the titration curve for an isopropanol solution of tetrabutylammonium hydroxide was in good agreement with that for the methanol solution at $\mathrm{pH}$ values smaller than 16 , a methanol solution of tetrabutylammonium hydroxide was used in the present study. If potentiometric titration is performed for weaker polyacids, isopropanol or DMSO as a titrant solvent should be used instead of methanol. The detection limit for the potentiometric titration was $\sim 5 \mathrm{mM}$ as the acid concetration, namely, a $C_{\mathrm{M}}$ of $\sim 6 \mathrm{mM}$ for $x=0.8$.

The potentiometric titration curves for weak polyacids have usually been analyzed by using $\mathrm{p} K_{\mathrm{a}}=\mathrm{pH}-\log (\alpha /(1-\alpha))$, where $\mathrm{p} K_{\mathrm{a}}$ and $\alpha$ are the negative logarithm of the dissociation constant and the degree of dissociation corresponding to the ratio of tetrabutylammonium hydroxide to MAA before titration, respectively. The $\mathrm{p} K_{\mathrm{a}}$ value for a small compound is constant, independent of $\alpha$, while that for a polyacid depends on $\alpha .{ }^{1,2}$ Figure 2 shows $\mathrm{p} K_{\mathrm{a}}$ versus $\alpha$ plots for various $x$ and $C_{\mathrm{M}}$ values. The $\mathrm{p} K_{\mathrm{a}}$ value of $\operatorname{Poly}\left(\mathrm{BuMA}_{1-x} \mathrm{MAA}_{x}\right)$ increased with increasing $\alpha$. The acid dissociation can be suppressed by strong electrostatic repulsions of the charged methacrylate anion unit $\left(\mathrm{MA}^{-}\right)$, as reported concerning aqueous polyacid solution systems. ${ }^{4-6}$ On the other hand, $\mathrm{p} K_{\mathrm{a}}$ increased with increasing $x$ for the same $\alpha$ (Fig. 2a). These results indicate that the distance between MAA and $\mathrm{MA}^{-}$is significant for acid dissociation. In resist polymers, carboxyl and hydroxyl groups are typical alkaline-soluble groups. When the $\mathrm{p} K_{\mathrm{a}}$ at $\alpha=0.5$ is defined as $\mathrm{p} K_{\mathrm{a}, 1 / 2}$, this value for $\operatorname{Poly}\left(\mathrm{BuMA}_{1-x} \mathrm{MAA}_{x}\right)$ is similar to that for resist polymers possessing a hydroxylhexafluoroisopropyl or carboxylfluoromethylidene group as a monomer unit $\left(\mathrm{p} K_{\mathrm{a}, 1 / 2}=\right.$ 10 - 13 in DMSO). ${ }^{9}$ The $\mathrm{p} K_{\mathrm{a}, 1 / 2}$ value for Poly $\left(\mathrm{BuMA}_{1-x} \mathrm{MAA}_{x}\right)$ is much greater than that of resist polymers having a 1carboxyl-1,2,2,2-tetrafluoroethyl group as a monomer unit $\left(\mathrm{p} K_{\mathrm{a}, 1 / 2}=5-6\right.$ in DMSO). ${ }^{9}$

At the same $C_{\mathrm{M}}$, the total MAA and $\mathrm{MA}^{-}$concentration $\left(C_{\mathrm{MAA}}\right)$ for $x=0.8$ is 2 -times that for $x=0.4$. The $\mathrm{p} K_{\mathrm{a}, 1 / 2}$ difference between $x=0.8\left(C_{\mathrm{MAA}}=10 \mathrm{mM}\right)$ and $x=0.4\left(C_{\mathrm{MAA}}=\right.$ $5 \mathrm{mM}$ ) was 1.5 at $C_{\mathrm{M}}=12.5 \mathrm{mM}$ (Fig. 2a). On the other hand,

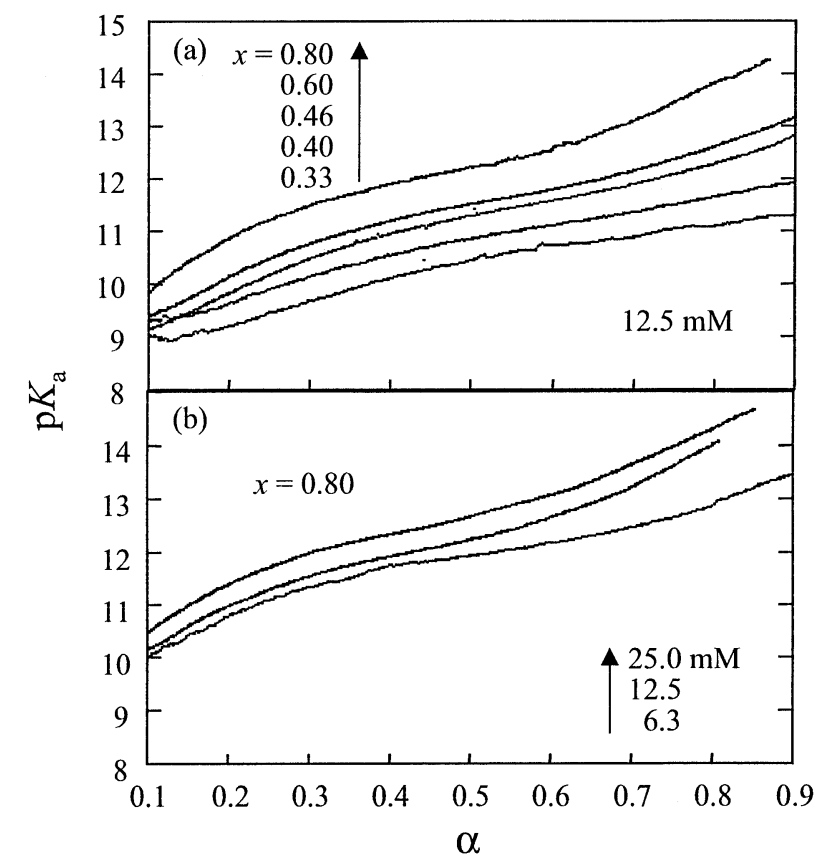

Fig. $2 \mathrm{p} K_{\mathrm{a}}$ values of Poly $\left(\mathrm{BuMA}_{1-x} \mathrm{MAA}_{x}\right)$ as a function of $\alpha$ at $C_{\mathrm{M}}$ $=12.5 \mathrm{mM}$ for $x=0.33-0.80$ (a) and at $C_{\mathrm{M}}=6.3-25.0 \mathrm{mM}$ for $x=$ 0.8 (b).

the $\mathrm{p} K_{\mathrm{a}, 1 / 2}$ values at $C_{\mathrm{M}}=12.5 \mathrm{mM}\left(C_{\mathrm{MAA}}=10 \mathrm{mM}\right)$ and 6.3 $\mathrm{mM}\left(C_{\mathrm{MAA}}=5 \mathrm{mM}\right)$ for $x=0.8$ were almost the same within the experimental error (Fig. 2b). Therefore, the polymer-polymer interaction is negligibly small at $\alpha$ values lower than $\sim 0.5$, and the polymer will be dissolved as a compact conformation in DMSO. However, the $\mathrm{p} K_{\mathrm{a}}$ versus $\alpha$ curve for $x=0.8$ slightly increased with increasing $C_{\mathrm{M}}$ at $\alpha$ values greater than $\sim 0.5$ (Fig. $2 b)$. Although the methacrylate polymers are expected to be hydrophobic, $\operatorname{Poly}\left(\mathrm{BuMA}_{0.2} \mathrm{MAA}_{0.8}\right)$ at higher $\alpha$ values possesses a high charge density in the single-polymer chains. The polymer chain is then expanded so that the polymerpolymer interaction will be slightly induced at a $C_{\mathrm{M}}$ value greater than $10^{-2} \mathrm{M}$. To discuss the neighboring effect of charged $\mathrm{MA}^{-}, \mathrm{p} K_{\mathrm{a}}$ versus $\alpha x$ was plotted, as shown in Fig. $3 ; \alpha x$ corresponds to the ratio of the $\mathrm{MA}^{-}$concentration to $C_{\mathrm{M}}$ in the single-polymer chains. The $\mathrm{p} K_{\mathrm{a}}$ versus $\alpha x$ plots fall almost on the same curve, indicating that the $\mathrm{p} K_{\mathrm{a}}-\alpha x$ curves are directly related by the amount of $\mathrm{MA}^{-}$in the same polymer chain, independent of $x$. It is concluded that the suppression of MAA dissociation is governed by the neighboring charged $\mathrm{MA}^{-}$in the individual polymer chains as the main component in the $C_{\mathrm{M}}$ range of $10^{-3}-10^{-2} \mathrm{M}$.

The solubility of a polymer in an aqueous tetramethylammonium hydroxide solution (developer) is one of the important properties of resist materials in determining the resolution and sensitivity. It has been reported that although Poly $\left(\mathrm{BuMA}_{1-x} \mathrm{MAA}_{x}\right)$ with a higher $x$ is easily dissolved in the developer, a complicated swelling behavior is observed during the developing processes. ${ }^{9}$ As discussed above, the $\mathrm{p} K_{\mathrm{a}}$ of the polymer will increase with the developing time. Furthermore, highly concentrated tetramethylammonium hydroxide is added to the polymer film surface so that $\alpha$ in the surface layer of the film alone will increase in the initial stage of the developing processes. Thus, the dissolution of the polymer will compete with the swelling of the polymer film. 


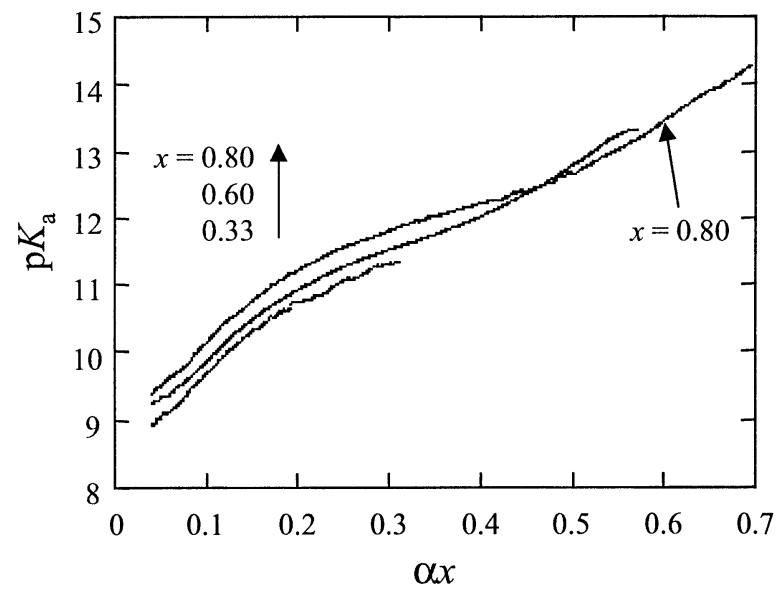

Fig. $3 \alpha x$ dependence of $\mathrm{p} K_{\mathrm{a}}$ of $\operatorname{Poly}\left(\mathrm{BuMA}_{1-x} \mathrm{MAA}_{x}\right)$ at $C_{\mathrm{M}}=12.5$ $\mathrm{mM}$ for $x=0.33,0.60$ and 0.80 .

\section{Conclusion}

The $\mathrm{p} K_{\mathrm{a}}$ values of $\operatorname{Poly}\left(\mathrm{BuMA}_{1-x} \mathrm{MAA}_{x}\right)$ were measured in DMSO by nonaqueous potentiometric titration. The copolymerization ratio dependence of the $\mathrm{p} K_{\mathrm{a}}$ versus $\alpha$ curve of Poly $\left(\mathrm{BuMA}_{1-x} \mathrm{MAA}_{x}\right)$ was successfully distinguishable by this technique so that the curves could be discussed in terms of a suppression of the dissociation of MAA by the neighboring $\mathrm{MA}^{-}$effect in the single-polymer chains. We consider that nonaqueous potentiometic titration is sufficient to analyze the dissociation and dissolution mechanisms of polyelectrolytes in organic solvents. In particular, valuable information regarding resist polymers can be obtained by the present technique.

\section{References}

1. L. Kotin and M. Nagasawa, J. Chem. Phys., 1962, 36, 873.

2. Y. Kawaguchi and M. Nagasawa, J. Phys. Chem., 1969, 73, 4382.

3. S. Kawaguchi, A. Yekta, and M. A. Winnik, J. Colloid Interface Sci., 1995, 176, 362.

4. M. Ullner, B. Jonsson, B. Soderberg, and C. Peterson, J. Chem. Phys., 1996, 104, 3048.

5. Y. Hirose, Y. Sakamoto, H. Tajima, S. Kawaguchi, and K. Ito, J. Phys. Chem., 1996, 100, 4612.

6. J. de Groot, G. J. M. Koper, M. Borkovee, and J. de Bleijser, Macromolecules, 1998, 31, 4182.

7. H. Suzuki, B. Wang, R. Yoshida, and E. Kokufuta, Langmuir, 1999, 15, 4283.

8. C. Wang, K. C. Tam, and R. D. Jenkins, J. Phys. Chem. B, 2002, 106, 1195 .

9. M. Toriumi, T. Itani, J. Yamashita, T. Sekine, and K. Nakatani, Proc. SPIE, 2002, 4690, 904.

10. M. J. Hanrahan and K. S. Hollis, Proc. SPIE, 1987, 771, 128.

11. K. Izutsu, "Electrochemistry in Nonaqueous Solutions", 2002, Wiley-VCH, Weinheim.

12. T. Tamura, H. Uehara, K. Ogawara, S. Kawaguchi, M. Satoh, and J. Komiyama, J. Polym. Sci., 1999, 37, 1523. 